\title{
Presidencialismo de coalizão: conceito e aplicação
}

Coalitional Presidentialism: concept and application

\section{Introdução}

Mais de três décadas após a publicação do famoso artigo de Sérgio Abranches (1988), o termo "presidencialismo de coalizão" continua presente tanto nos debates acadêmicos quanto nas conversas sobre política no dia a dia. Embora, geralmente, a população e grande parte da mídia a considere como uma simples forma de se fazer um "toma lá, dá cá", a construção de coalizões de governo está longe de ser uma simples troca de favores na política. Com efeito, as coalizões governamentais são acordos em que os partidos políticos e seus líderes concordam em compartilhar recursos políticos a fim de alcançar metas em comum (RENIU; ALBALA, 2012).

Além disso, deve-se ter em mente que, de forma contrária àquilo que o artigo de Abranches dá a entender, o presidencialismo de coalizão não é um fenômeno típico e exclusivo da realidade brasileira ${ }^{4}$, apesar do protagonismo de autores brasileiros em um grande número de contribuições para o entendimento do presidencialismo

\footnotetext{
1 Mestrando em Ciência Política na Universidade de Brasília (UnB). Brasília, DF, Brasil. E-mail: $<$ lucasalmeidacouto040@gmail.com>

2 Mestrando em Ciência Política na Universidade de Brasília (UnB).Brasília, DF, Brasil. E-mail: <andelitons@gmail.com>

3 Graduando em Ciência Política pela Universidade de Brasília (UnB). Brasília, DF, Brasil. E-mail: $<$ bernardolivramento3@gmail.com>

4 Recentemente, Abranches (2018) renovou a discussão sobre o presidencialismo de coalizão, trazendo novos elementos para análise, como a composição bicameral das coalizões e o gasto orçamentário em cada governo. Ainda assim, seu foco paira, sobretudo, no caso brasileiro.
} 
multipartidário (POWER, 2015). Na verdade, o presidencialismo de coalizão é bastante difundido entre os próprios países latino-americanos (DEHEZA, 1997; CHASQUETTI, 2001). Como exemplo disso, as coalizões governamentais representam o modus operandi da política chilena pelo menos desde a época do processo de redemocratização no país (ALBALA, 2017a).

Consequentemente, os estudos destinados a compreender o presidencialismo de coalizão não podem se desprender do que se conhece como a "teoria das coalizões" (coalition theories), que é justamente a literatura internacional sobre as coalizões. De forma simples, as coalizões de governo não são traços somente brasileiros, tampouco são exclusivamente presidencialistas. Na verdade, inicialmente, a discussão sobre as relações interpartidárias em um contexto coalizacional se dedicou a tratar apenas dos casos parlamentaristas. De início, deve-se notar que esse viés não foi genuinamente proposital. Como os estudos acerca da formação e da distribuição de ministérios entre os partidos das coalizões governamentais tiveram o seu início entre as décadas de 1950 e 1970, muitos países presidencialistas foram descartados como locus de análise por serem regidos por regimes ditatoriais à época. Com efeito, o número de regimes presidencialistas democráticos só aumentou, de fato, a partir da terceira onda de democratização, na qual os países situados no continente americano ou inauguraram um regime democrático pela primeira vez, ou deixaram de ser uma autocracia propriamente dita (CAREY, 2005; GARRETÓN, 1997). A partir disso, realmente seria irracional estudar coalizões governamentais em sistemas nos quais os cargos governamentais eletivos não eram preenchidos a partir de eleições recorrentes e justas.

Contudo, em um segundo momento, a desconsideração do presidencialismo de coalizão realmente se configurou como uma escolha acadêmica expressa, cuja justificativa metodológica foi a de que o sistema presidencial não seria capaz de gerar incentivos institucionais para a cooperação entre os diferentes atores políticos, o que o levaria invariavelmente à instabilidade democrática (LINZ, 1990; VALENZUELA, 1994). E, quando não acusado por si só 
como ineficaz, pensou-se que a combinação entre presidencialismo e multipartidarismo seria imprópria para o prosseguimento de regimes democráticos, visto que a briga entre os diferentes setores do governo seria praticamente inevitável (MAINWARING, 1993).

Foi somente no final da década de 1990 e no começo dos anos 2000 que ocorreu o entendimento de que o Executivo e o Legislativo cooperam entre si por meio da formação de coalizões tanto em regimes parlamentaristas quanto em presidencialistas. Essa situação deriva da constatação empírica de que tais arranjos de governo não eram tão anormais quando o partido presidencial não conseguia alcançar o status majoritário no Legislativo sozinho (CHEIBUB; PRZEWORSKI; SAIEGH, 2004; CHEIBUB, 2007). Pelo lado teórico, a constituição do presidencialismo de coalizão se justifica à medida que o presidente não se importa somente com o fato de estar no ofício por quatro anos, mas também com as políticas a serem emplacadas durante esse período. Nesse tocante, pouco importa se o presidente realmente possui valores inerentes quanto às suas políticas preferidas, ou se ele ou ela apenas deseja usá-las como plataforma eleitoral. O importante é que, apesar da rigidez dos mandatos entre Executivo e Legislativo no presidencialismo, os presidentes possuem anseios políticos e eleitorais (ALEMÁN; TSEBELIS, 2011).

Contudo, a literatura brasileira ainda carece de aproximação com a ampla literatura sobre a teoria das coalizões. Dessa forma, com o propósito de estabelecer esse vínculo neste artigo, temos as seguintes perguntas como nosso foco: "O que são coalizões?"; e "Do que se trata o conceito presidencialismo de coalizão?" A partir dessas perguntas, temos por objetivo apresentar as discussões teóricas em torno do que são as coalizões sob a perspectiva da divisão da literatura em quatro principais gerações, esclarecer onde o presidencialismo entra na discussão, apresentar um breve panorama das coalizões existentes na América Latina e expor algumas das atuais direções de pesquisas no que tange às coalizões presidencialistas. 
O artigo está segmentado da seguinte forma: na próxima seção, apresentamos as diferentes fases de estudos sobre coalizões, começando com os estudos que abordam as coalizões simplesmente como objetos lógico-matemáticos, no início da primeira geração, até a mais recente onda de pesquisadores interessados em compreender o fenômeno da congruência entre as coalizões em diferentes níveis de governo. Em seguida, discutimos o presidencialismo sob o enfoque das coalizões, tratando de problemas gerais ao redor da definição de um governo presidencialista com coalizões, e apresentamos um breve resumo do presidencialismo de coalizão com a América Latina como pano de fundo. Por fim, dedicamo-nos a expor novas tendências na literatura, mais especificamente os debates sobre a gestão de coalizões e as ferramentas presidenciais, a dinâmica bicameral no presidencialismo e, por fim, coalizões como fenômeno pré-eleitoral e vertical.

\section{Gerações de estudos sobre coalizões}

Quando o assunto em questão são os governos de coalizão, é necessário saber a que tipo de fenômeno político-institucional estamos nos referindo. No caso de conceitos amplamente difundidos por meio de inúmeros veículos de comunicação, assim como utilizados em vários campos, é sempre pertinente relembrar e delimitar do que estamos falando e, principalmente, do que não estamos falando.

Para tanto, são considerados governos de coalizão aqueles em que há a participação de diferentes partidos políticos no gerenciamento da máquina estatal, ou, se preferir, em que o poder da esfera pública é dividido entre dois ou mais partidos políticos (RENIU; ALBALA, 2012). É de suma importância não confundir as coalizões com os governos que, de tempos em tempos, obtêm apoio legislativo para algumas pautas. Tampouco se deve pensar que somente a presença de alguns ministros com vínculos partidários é suficiente para a existência de um governo de coalizão (ALBALA, 2018).

Porém, a conceituação sobre o que são as coalizões não tem sua origem meramente ex nihilo. Esse conceito é fruto de 
aproximadamente 70 anos de pesquisa. Graças à extensa bibliografia já produzida, podemos separar a literatura sobre as coalizões, para fins didáticos, em quatro gerações de estudos (ALBALA, 2018; BROWNE; FRANKLIN, 1986). A discussão sobre cada uma delas é feita a seguir.

\section{Primeira Geração}

O que chamamos de primeira geração dos estudos de coalizão nada mais é do que a abertura de um novo campo de estudos feita por um conjunto de pesquisadores entre os anos 50 e 70. Como um campo inexplorado até então, os autores da primeira geração foram responsáveis por estabelecer a primeira percepção sobre o que seria uma coalizão e como ela operaria. Dessa forma, trata-se de uma etapa de estudos eminentemente teórica, na qual se buscou construir uma série de proposições sobre o funcionamento das coalizões.

A princípio, as teorias desenharam jogos ideais e consideraram os atores como indivíduos livres, sem quaisquer constrangimentos feitos pela sociedade ou pelas instituições (CAPLOW, 1956). Esses estudos, no limite, criaram apenas alterações em um jogo ideal, como uma dinâmica de força ou de poder pré-estabelecido para inferir como coalizões de indivíduos se comportariam em um plano hipotético.

No fundo, criaram-se teorias sobre coalizões em ambientes neutros e, portanto, sem a consideração de contextos políticos. Desse modo, as primeiras construções teóricas acerca das coalizões não passaram de meros exercícios de teoria dos jogos e de operacionalização de diferentes modelos de escolha racional, sem qualquer associação com o estudo de um país ou de um sistema em específico. Não obstante, as críticas às teorias foram muitas, principalmente por terem suposições extremamente restritas ao campo das ideias e não buscarem fundamentos na realidade (ALBALA, 2018).

No campo dos governos de coalizão propriamente dito, em relação à composição partidária das coalizões, a principal proposição teórica construída nessa fase diz respeito à formação de uma 
coalizão mínima vencedora (RIKER, 1962). Em tese, argumenta-se que o que garante a viabilidade de uma coalizão é o seu tamanho no parlamento. Em outras palavras, o fato de ela se constituir e gerar benefícios aos seus participantes é um resultado direto da sua dimensão legislativa. Basicamente, formar-se-iam as coalizões que garantem uma maioria mínima no Legislativo $(50 \%+1$ dos parlamentares), uma quantidade suficiente para que os participantes da coalizão "vençam" o jogo e, portanto, possam auferir os benefícios da vitória com o menor custo, já que o "prêmio" de comandar o governo é repartido com o menor número possível de atores.

As suposições desse tipo de teoria são claras: enquanto jogadores racionais, os membros da coalizão buscam apenas ser maioria e obter vitória em um jogo de informação simétrica. Vale ressaltar que a construção teórica sobre o tamanho das coalizões é extrema: elas são mínimas no ponto em que a perda de somente um parlamentar já é suficiente para a perda do status majoritário. Como desdobramento da teoria rikeriana, Leiserson (1966) ainda apresenta a ideia de que os partidos não querem somente formar coalizões mínimas com base na distribuição partidária, mas também buscam construir coalizões com o menor número possível de partidos políticos. Nesse ponto, o raciocínio é o de que quanto menor o número de partidos na coalizão, mais fácil é a barganha interpartidária no que concerne a "qual partido comanda qual ministério".

Porém, essas proposições teóricas sofriam com um grave problema: tomou-se como certo que a motivação dos partidos políticos era única e exclusivamente ser parte do governo. Como modo de expandir os modelos explicativos, outros autores ressaltaram que os partidos também se interessam por questões relacionadas às políticas públicas. Desse modo, ainda com base na noção espacial, argumentou-se que as coalizões que se formam na prática são aquelas que possuem a menor distância ideológica entre seus membros (AXELROD, 1970).

Embora tenha sido muito discutido a pergunta "quais partidos compõem as coalizões?", também se buscou responder "como os partidos da coalizão repartem os benefícios do governo entre si?". 
Nesse ponto, pode-se falar ainda que uma das grandes contribuições dessa geração foi a proposição do princípio da proporcionalidade entre contribuições e benefícios de cada participante da coalizão. Exemplificando: o que se propõe é que, caso contribua com $15 \%$ dos recursos, o membro receberia o equivalente a $15 \%$ dos benefícios disponíveis (GAMSON, 1961).

Ainda assim, muitos problemas foram encontrados com as pesquisas realizadas por essa geração. Diversas temáticas propriamente políticas, como a influência da coalizão incumbente (FRANKLIN; MACKIE, 1983), e metodológicas, como a simples realização de testes empíricos (ALBALA, 2018), foram simplesmente ignoradas. De todo modo, tudo isso não se deu ao acaso. A princípio, os membros da primeira geração estudaram as coalizões como um simples fenômeno lógico-matemático, não necessariamente inerente a um sistema político, tema que nos é de interesse neste artigo. Não custa destacar que não havia estudos prévios em relação à temática das coalizões. Desse modo, levando em conta o contexto das primeiras pesquisas, embora as críticas que lhe são dirigidas sejam realmente justas, é inegável que as considerações iniciais dessa fase foram valiosas, se não fundamentais, para o prosseguimento dos estudos destinados a compreender o fenômeno dos governos de coalizão.

\section{Segunda Geração}

Por outro lado, a característica marcante dos estudos da segunda geração foi exatamente o teste empírico das proposições teóricas desenvolvidas pela primeira geração. Para isso, o locus de análise dos testes foram os países parlamentaristas e multipartidários da Europa no período pós-Guerra. De forma geral, os demais traços dessa fase que também são dignos de menção são a adoção de desenhos comparativos de pesquisa, o uso de métodos dedutivos e quantitativos, bem como a negligência do caráter histórico dos gabinetes e das diferenças institucionais entre cada país.

É de se notar que, nesse momento, não houve nenhuma análise sobre o funcionamento das coalizões no presidencialismo. Porém, 
isso não é fruto apenas de um viés de seleção por parte dos autores. $\mathrm{Na}$ verdade, as próprias teorias referentes à composição partidária e à distribuição de pastas ministeriais aos membros do gabinete foram desenvolvidas à vista dos casos parlamentaristas.

Mas, então, por que não houve o desenvolvimento de teorias específicas para coalizões sob o regime presidencialista? Primeiramente, deve-se atentar que os estudos da segunda geração tiveram seu início em meados de 1970. Nesse período, não existiam muitos países presidencialistas com um regime democrático de governo. Portanto, a opção de estudar o arranjo de coalizões em sistemas presidenciais sequer foi considerada à época.

Além disso, duas décadas mais tarde, desenvolveu-se a ideia de que o regime presidencialista não geraria incentivos à cooperação entre o Legislativo e o Executivo de tal forma que a formação de coalizões só ocorreria em situações completamente excepcionais (LINZ, 1990, 1994; MAINWARING, 1993; VALENZUELA, 1994). Na prática, adianta-se que esse pensamento só foi superado na terceira geração, na qual se constatou a existência de governos de coalizão também nos regimes presidenciais (CHEIBUB, 2007).

De qualquer modo, a grande inquietação da segunda fase foi o mau desempenho dos modelos teóricos para a predição de quais partidos comporiam a coalizão governista (BROWNE, 1971; DE SWAAN, 1973). Em profundo contraste, o princípio da proporcionalidade de Gamson apresentou incrível suporte empírico. A partir da operacionalização de que os recursos dos partidos à coalizão são as cadeiras na câmara baixa, e que as recompensas são as pastas ministeriais, inúmeros trabalhos apontaram que os ministérios são distribuídos de forma quase proporcional ${ }^{5}$ aos membros da coalizão, com base na porcentagem de assentos de cada partido da coalizão na câmara baixa (BROWNE; FRANKLIN, 1973; BROWNE; RICE, 1979; MORELLI, 1999; LAVER; SCHOFIELD, 1990). Porém, a

5 A proporcionalidade não é exata porque existem erros sistemáticos nessa relação. Eles são apontados por diferentes estudos. Enquanto os menores partidos da coalizão costumam ser favorecidos à medida que recebem maiores cotas ministeriais do que indicam os seus pesos legislativos, os maiores tendem a receber menos ministérios do que o esperado segundo o princípio de proporcionalidade indicada por Gamson. 
despeito dos pontos positivos, há um grave problema com a relação proposta por Gamson: ela carece de um mecanismo causal explícito. A proporção entre ministérios e cadeiras asseguradas na câmara baixa surgiu, na verdade, da construção de uma mera hipótese intuitiva por parte de Gamson (INDRIDASON, 2015).

Desse modo, o resultado dos estudos da segunda geração implicou em uma desilusão coletiva na literatura referente às coalizões, tendo em vista que os modelos teóricos tão bem elaborados pela primeira geração mostraram resultados preditivos medíocres, enquanto o princípio que nem ao menos foi construído teoricamente foi o que teve melhor apoio empírico para explicar a distribuição dos ministérios entre os membros do gabinete.

Uma primeira consequência disso foi a grande antipatia que a literatura desenvolveu com o uso dos modelos formais. Por que continuar a construir modelos se eles não possuem poderes preditivos bons o suficiente? Embora seja compreensível a insatisfação com a sua falta de poder explicativo, é necessário fazer uma mínima defesa da relevância dos modelos formais para a Ciência Política. Como toda teoria, os modelos formais são uma construção prévia investigativa destinada a explicar o porquê do acontecimento de certo fenômeno. A partir disso, não é extraordinário que os resultados previstos pela teoria não sejam perfeitamente equivalentes com os achados empíricos do fenômeno estudado, até mesmo porque os resultados logicamente possíveis segundo a teoria são mais amplos do que os desdobramentos da realidade concreta. De certa forma, o mau desempenho dos modelos formais é consequência da sua busca por uma explicação generalizável do processo de formação das coalizões.

Com isso, o desapontamento com os achados empíricos da segunda geração representou um terreno fértil para a expansão dos métodos e das técnicas de pesquisa utilizadas para compreender a formação e a distribuição dos recursos dos governos de coalizão. 


\section{Terceira Geração}

Por sua vez, os fatores mais relevantes que podem ser elencados para classificar a terceira geração são aqueles centrados nas instituições e nos aspectos sociológicos das coalizões governamentais (ALBALA, 2018). Tal qual a segunda geração, essa terceira fase também se centra na busca de dados empíricos. Entretanto, a grande novidade é que, agora, as pesquisas adotam uma abordagem voltada para a indução. Além disso, apesar de ainda pressupor certa racionalidade dos atores, a terceira geração tem uma forte crítica à ideia de equilíbrio informacional, que representa a base teórica da primeira geração. Como visto anteriormente, essa rejeição enfática é uma reação ao pífio desempenho da relação entre a teoria e a prática das coalizões. Como bem resume Pridham (1986), a rejeição pelos modelos formais representa uma tentativa de aproximar a teoria e a empiria no que concerne aos governos de coalizão.

Fora isso, é marcante a importância do contexto para a terceira geração (BROWNE; FRANKLIN, 1986). Franklin e Mackie (1983), por exemplo, ressaltam o quão importantes são não apenas o tamanho, a diversidade ideológica e a familiaridade entre os partidos que compõem as coalizões, mas também como cada país apresenta a sua específica peculiaridade em um dado espaço e tempo.

A terceira onda também se notabilizou pela ampliação dos sistemas políticos estudados. Diferentemente das duas primeiras, passou-se a estudar os governos de coalizão em países fora do continente europeu, especialmente, e como grande novidade, em regimes presidencialistas. Isso, no entanto, não ocorreu de maneira súbita.

De início, vários autores defenderam expressamente que as coalizões somente se formariam em contextos completamente atípicos nos sistemas presidenciais, uma vez que esse regime não estimularia, por si só, a cooperação entre os diferentes ramos de governo. A partir disso, afirmou-se, inclusive, que a adoção do presidencialismo como regime de governo era perigosa até mesmo para a manutenção democrática (LINZ, 1978, 1990; STEPAN; SKATCH, 1993; VALENZUELA, 1994). Em uma pequena retratação, 
Mainwaring (1993) chegou a argumentar que o problema não era intrinsecamente o presidencialismo, mas, sim, a sua vinculação com o multipartidarismo.

Contudo, todas essas asserções careceram de respaldo empírico, o que se mostrava simplesmente inaceitável, tendo em vista o estágio da discussão sobre coalizões. A questão é que a ocorrência de governos de coalizão não se mostrou nada anormal nos regimes presidencialistas (CHEIBUB; PRZEWORSKI; SAIEGH, 2004; CHASQUETTI, 2001; DEHEZA, 1997). Na verdade, o número de governos de coalizão se mostrou tão considerável que diferentes linhas de estudo surgiram para estudar especificamente o comportamento dos gabinetes presidenciais, como ficará evidenciado na próxima seção.

Ademais, outra característica dessa geração é que se supõe que os políticos possuem outras motivações que não a busca por postos (office-seeking) e/ou a busca por políticas públicas (policy-seeking), a saber: o vote-seeking (STROM, 1990). Basicamente, essa nova motivação nos indica que os partidos mudam seu comportamento com o propósito de captar mais votos nas próximas eleições.

Albala (2018) resume os principais focos da terceira geração em cinco tópicos:

i. Consideração das condições institucionais capazes de promover incentivos e constrangimentos à composição de coalizões, com um especial interesse a respeito das regras eleitorais, interações entre o Executivo e o Legislativo e prerrogativas para os líderes de governo (STROM; BUDGE; LAVER, 1994);

ii. Busca pelas motivações políticas e estruturais voltadas a aspectos ideológicos e organizacionais. Esse foco direciona particular interesse a respeito da interação de fatores da cultura política;

iii. O 'timing' das coalizões, que envolve uma análise mais ampla em relação ao aspecto temporal das coalizões e que transcende a fase de negociação, formação de governo e a dissolução dos acordos, indo até os acordos pré-eleitorais, como tendem a fazê-lo um número considerável de trabalhos 
recentes (ALBALA, 2017a; CARROL; COX, 2007; CHIRU, 2015; DEBUS, 2009; FREUDENREICH, 2016; GOLDER, 2006);

iv. O gerenciamento dos governos de coalizão, com particular interesse nos assuntos voltados a como garantir apoio majoritário no Legislativo, seja por meio da utilização de aspectos organizacionais, seja por meio das instituições formais, seja até mesmo através das instituições informais. (CHAISTY; CHEESEMAN; POWER, 2014; RAILE; PEREIRA; POWER, 2011); e por fim:

v. O ambiente de negociação e "prestação de contas" das coalizões, fatores esses que afetam a estabilidade de uma coalizão.

\section{Quarta Geração}

Como visto, todas as três gerações expostas previamente têm as suas especificidades. A primeira se dedicou a teorizar sobre a existência das coalizões e a construir modelos que justificassem os seus comportamentos. Já a segunda buscou testar empiricamente a validade das teorias acerca das coalizões nos regimes parlamentaristas europeus. Em contrapartida, a terceira ampliou o escopo de pesquisa, analisando não somente as coalizões sob o parlamentarismo, mas também sob o presidencialismo. Mais do que isso, a partir da realização de trabalhos indutivos, a terceira geração também prescindiu ao uso exclusivo de métodos dedutivos no estudo das coalizões, incorporando, também, às suas análises variáveis institucionais e sociais.

Porém, apesar de todas as diferenças, essas três fases de estudos sobre coalizões compartilham duas importantes similaridades entre si: a premissa de que os partidos políticos atuam como blocos unitários; e a concentração dos estudos na esfera nacional. Particularmente, a inovação promovida pela quarta leva de trabalhos é justamente a subversão desses dois pontos (ALBALA, 2018).

De fato, o questionamento sobre a suposta homogeneidade dos partidos políticos não é de modo nenhum algo novo na literatura. As críticas a essa pressuposição datam pelo menos desde os 
primeiros estudos acerca do funcionamento das coalizões. Luebbert (1983), por exemplo, destaca que, por vezes, convencer as próprias facções sobre as vantagens de participar de um gabinete de coalizão é mais difícil do que a própria celebração do acordo com os outros partidos.

O interessante é que a crítica aos trabalhos que não consideram a perspectiva intrapartidária persiste até hoje. O problema é que a sua não-consideração não se deve à simples ignorância dos autores, mas sim às dificuldades de inserir os conflitos intrapartidários nas abordagens empíricas, especialmente nas de cunho quantitativo. Todavia, outras áreas da Ciência Política já começaram a superar esse problema metodológico. Como exemplo disso, ao estudarem a dinâmica da organização partidária, VanDusky-Allen e Heller (2013) argumentam que, a fim de antecipar e evitar possíveis comportamentos dissonantes dos seus membros nas duas casas legislativas, a existência de sistemas bicamerais fortes induz os partidos a centralizarem os respectivos processos de seleção de candidatos disponíveis para as eleições.

Assim, o grande mérito da quarta geração foi exatamente incluir o aspecto da heterogeneidade dos partidos na discussão sobre coalizões a partir da consideração do pacto federativo, mais precisamente por meio da comparação das coalizões em âmbito nacional e local. Com isso, foram superados dois problemas na literatura referente às coalizões de uma única vez: a negligência da dinâmica interna dos partidos e a análise exclusiva das coalizões de caráter nacional. Sobretudo, o principal interesse dessa geração consiste em mensurar a congruência da verticalização das coalizões. Apesar de existir uma pluralidade de definições sobre o que é a congruência entre as coalizões nacional e regional, convém destacar, ao menos, a conceituação apresentada por Albala e Reniu (2018) de que os governos de coalizão são congruentes quando as coalizões regionais não incluem os partidos de oposição à coalizão nacional como membros dos seus acordos subnacionais.

No entanto, essa nova abordagem só é capaz de analisar os países que mesclam, concomitantemente, os arranjos federativos 
e coalizacional de governo. O problema é que o número de casos com essas características não é abundante. Mais ainda, os países que os combinam não são predominantemente presidencialistas ou parlamentaristas. Assim, como consequência disso, os estudos da quarta geração, diferentemente dos trabalhos da terceira, dificilmente conseguem realizar estudos comparados somente com regimes parlamentaristas ou apenas com regimes presidencialistas. Ante isso, as soluções são a realização de estudos de caso (BORGES; 2019; BORGES; LLOYD, 2016), ou a comparação com poucos casos (BORGES; ALBALA; BURTNIK, 2017). O próprio livro de Albala e Reniu (2018) é uma coleção de diferentes estudos de casos. Embora seja um trabalho destinado a analisar regras institucionais, vale destacar que o texto de Clerici e Scherlis (2014) é um raro exemplo de investigação comparativa nessa geração. De qualquer modo, não seria surpreendente o surgimento de estudos empenhados a comparar as coalizões entre os regimes de governo - ou seja, pesquisas que envolvessem uma análise transversal de sistemas parlamentares e presidenciais no que tange à congruência das coalizões.

Portanto, podem-se sumarizar os principais traços desta quarta geração nos seguintes pontos: a devida apreciação empírica da complexidade das relações intrapartidárias, o exame concomitante das coalizões nas esferas nacionais e subnacionais e, por fim, a utilização de desenhos de pesquisa voltados à compreensão de poucos ou até mesmo um único caso.

A partir de toda discussão exposta nesta seção, o Quadro 1 sumariza as principais características e limitações de cada uma das gerações de estudo das coalizões governamentais. Deve-se atentar que a separação da literatura em diferentes ondas constitui somente um exercício didático. Em outras palavras, não se pode associar um texto sobre coalizões à determinada geração apenas pelo período em que foi publicado. Como exemplo disso, Budge e Laver (1993) estudam o quão importante é o aspecto ideológico para a formação das coalizões a partir do exame de diversos programas eleitorais de países europeus. Se fôssemos seguir a simples divisão temporal, esse 
trabalho deveria ser listado como exemplar dos trabalhos produzidos pela terceira fase. No entanto, as características deste estudo são compatíveis com os demais estudos da segunda geração. Assim, faz-se necessária a advertência de que, em certa medida, as ondas de estudos se sobrepõem temporalmente, sendo sempre indispensável a análise do conteúdo trazido pelas pesquisas.

Quadro 1 - Resumo das quatro gerações de estudos sobre as coalizões

\begin{tabular}{|c|c|c|c|c|c|}
\hline Geração & Período & Expoentes & Metodologia & Contribuições & Principais limitações \\
\hline Primeira & $1950-1970$ & $\begin{array}{c}\text { Axelrod (1970), } \\
\text { Gamson (1961), Leiserson } \\
\text { (1966), Riker (1962) }\end{array}$ & $\begin{array}{l}\text { Dedução e méto- } \\
\text { dos quantitativos }\end{array}$ & $\begin{array}{l}\text { Primeira elaboração de } \\
\text { teoria sobre o funciona- } \\
\text { mento das coalizões }\end{array}$ & Falta de testes empíricos \\
\hline Segunda & $1970-1990$ & $\begin{array}{c}\text { Browne (1971), } \\
\text { Browne e Franklin (1973), } \\
\text { Budge e Laver (1986), } \\
\text { Laver e Schofield (1990) }\end{array}$ & $\begin{array}{l}\text { Dedução e méto- } \\
\text { dos quantitativos }\end{array}$ & $\begin{array}{l}\text { Realização de testes } \\
\text { empíricos a partir da } \\
\text { teoria desenvolvida pelos } \\
\text { estudos anteriores }\end{array}$ & $\begin{array}{l}\text { Foco excessivo em } \\
\text { estudos comparados e vício } \\
\text { metodológico quantitativo }\end{array}$ \\
\hline Terceira & $1985-$ & $\begin{array}{l}\text { Chasquetti (2001), } \\
\text { Cheibub et al. (2004), } \\
\text { Pridham (1986), } \\
\text { Strom (1990) }\end{array}$ & $\begin{array}{l}\text { Predomínio } \\
\text { da induçãoe } \\
\text { multimétodos }\end{array}$ & $\begin{array}{l}\text { Estudos contextuais, foco } \\
\text { institucional e conside- } \\
\text { ração das coalizões em } \\
\text { regimes presidenciais }\end{array}$ & $\begin{array}{l}\text { Visão negativa dos modelos } \\
\text { formais e perpetuação } \\
\text { da desconsideração das } \\
\text { questões intrapartidárias }\end{array}$ \\
\hline Quarta & 2010 & $\begin{array}{c}\text { Borges (2017), } \\
\text { Borges et al. (2017), } \\
\text { Clerici e Scherlis (2014) }\end{array}$ & Multimétodos & $\begin{array}{l}\text { Análise das questões } \\
\text { intrapartidárias e estudo } \\
\text { das coalizões para além } \\
\text { da esfera nacional }\end{array}$ & $\begin{array}{c}\text { Escassez de estudos } \\
\text { comparados }\end{array}$ \\
\hline
\end{tabular}

Fonte: Elaborado pelos autores.

\section{O presidencialismo de coalizão}

O presidencialismo possui uma série de pressuposições básicas - e algumas podem rapidamente demonstrar o que esse sistema de governo exige: os eleitores devem escolher o seu presidente de forma direta, o mandato do presidente é fixo e independe do voto do Legislativo, o presidente eleito comanda o executivo nomeando seu governo e o presidente eleito tem certos e limitados poderes legislativos (LIJPHART, 1992; SHUGART; CAREY, 1992). 
Com o advento do multipartidarismo, a lógica da governabilidade no presidencialismo se torna complexa. Como amostra desse sistema, os países latino-americanos ofereceram diferentes e múltiplos exemplos de presidentes eleitos cujos partidos não obtiveram maioria no Legislativo. A solução dada a esse problema foi a de formação de uma coalizão de diferentes partidos, detendo a maioria no Legislativo quando juntos. Seria possível, claro, governar de forma minoritária, com o próprio partido do presidente e com negociações ad hoc.

Entretanto, em igual consonância com os estudos da terceira geração, que apontaram que as coalizões de governo também existem nos regimes presidencialistas, cabem as seguintes perguntas: como a literatura define o que é o presidencialismo de coalizão? Será que só a presença de ministros de outros partidos basta para caracterizar o gabinete como de coalizão?

Particularmente, essas perguntas se tornam interessantes na medida em que, em comparação com os primeiros-ministros, os presidentes contam com maior liberdade para nomear ministros que não tenham vínculos partidários. Apesar disso, no entanto, deve-se atentar que nem todos os presidentes dispõem de igual poder e liberdade para montar o gabinete ao seu modo. Araújo, Silva e Vieira (2016) indicam que o grau de dominância do chefe do Executivo em relação ao seu próprio gabinete varia de acordo com a capacidade do presidente de escolher e dispensar os ministros, os requisitos para se tomar posse do cargo ministerial e os poderes legislativos dos ministros. Esse adendo é importante porque, por muito tempo, autores, como Lijphart (1992), consideraram que os presidentes eram completamente livres para construir os seus gabinetes. Com efeito, chegou-se até considerar o poder dos presidentes frente aos gabinetes como um traço distintivo do presidencialismo em relação ao parlamentarismo.

Enfim, não existe um consenso na literatura sobre a definição do que é uma coalizão de governo nos sistemas presidencialistas (AMORIM NETO, 2000). Autores como Abranches (1988), Cheibub (2007) e Deheza (1997) parecem considerar a mera presença de 
ministros partidários como condição suficiente para a existência de um gabinete de coalizão. Por outro lado, Amorim Neto (1994, $1998,2000)$ e Chasquetti $(2001,2006)$ fazem a ressalva de que um ministro com vínculo partidário pode estar no gabinete simplesmente pela sua relação pessoal com o chefe do Executivo. Desse modo, o ministro não estaria representando propriamente seu partido no governo, mas sim seus próprios interesses. Com outras palavras, a presença de um ministro partidário não indicaria por si só a existência de um acordo entre o partido presidencial e o partido do ministro.

O problema é que a falta de consenso sobre o que é um governo de coalizão leva a diferentes análises sobre o presidencialismo de coalizão. A nosso ver, duas definições parecem ser as mais adequadas nesse assunto. Como visto na introdução, coalizões são frutos de acordos críveis entre diferentes partidos para a coordenação do governo. Com base nisso, mesmo que tenha sido pensada para contextos parlamentaristas, a conceptualização de Strom (1990) reflete bem a necessidade de estabelecer pactos interpartidários. Em suma, para Strom, as coalizões são caracterizadas pelo conjunto de partidos que acordam seguir metas comuns mediante a troca de recursos para cumpri-las e a distribuição das recompensas pela sua conquista.

Ademais, outra definição pode ser extraída da tipologia construída por Amorim Neto $(1994,1998)$ sobre os gabinetes presidenciais. Nela, Amorim Neto especifica que os gabinetes de coalizão são aqueles que possuem o acordo do presidente com, no mínimo, dois partidos e o critério de seleção ministerial partidário ou misto. $\mathrm{O}$ acordo do presidente com os partidos é autoexplicativo, mas melhor atenção deve ser dada aos parâmetros de seleção dos ministros. A diferença entre o partidário e o misto é que o primeiro tem o gabinete somente com ministros de perfil partidário, ao passo que o segundo apresenta ministros partidários e independentes.

O mais interessante é que Amorim Neto (1998, p. 8-10) não se limita a classificar somente o que é um gabinete de coalizão, mas também um gabinete de cooptação. A semelhança é que ambos 
adotam critérios mistos ou completamente partidários para a seleção dos ministros. A grande diferença está justamente na realização de acordos com os partidos: ao passo que o governo de coalizão requer estritamente o acordo interpartidário, o de cooptação não realiza acordo com nenhum partido, nem mesmo com o próprio partido presidencial.

Mas como constatar empiricamente se houve ou não o pacto entre os partidos? Amorim Neto (1994) aponta para três soluções. Primeiramente, pode-se acompanhar os relatos da mídia sobre a formação do governo. Entretanto, isso demandaria muito tempo e estaria sujeito ainda ao viés proposto pelas próprias reportagens. Como saídas mais válidas, é possível verificar o grau da coalescência ${ }^{6}$ e da percentagem de ministros partidários no gabinete. Assim, Amorim Neto (1998, p. 16) caracteriza que os governos de coalizão são aqueles que apresentam ambas as medidas maiores do que $50 \%{ }^{7}$. Todavia, nada impede que o pesquisador ou o analista adotem regras de corte mais rigorosas para a definição dos gabinetes de coalizão, estipulando as medidas para níveis situados entre $60 \%$ e $70 \%$. Para além disso, também se pode olhar para os aspectos sociológicos da construção das alianças interpartidárias. Por vezes, a simples análise da proporção entre ministérios e cadeiras no Legislativo e da proporção de ministros independentes não captura os acordos mais profundos realizados em uma dada coalizão. Um claro exemplo disso foram os governos da Concertación no Chile, que buscaram fazer acordos desde a esfera local até a nacional. $\mathrm{Na}$ verdade, os partidos componentes da Concertación lançavam candidatos únicos para todos os postos eletivos existentes no Chile de 1990 a 2008.

6 A coalescência não é nada mais do que a proporção entre pastas ministeriais e o número de assentos de cada partido da coalizão na câmara baixa. O argumento é que os governos de coalizão distribuiriam, ao menos de certo modo, os ministérios de modo proporcional ao peso legislativo de cada membro. Embora seja uma boa medida, é surpreendente que ela considere somente as cadeiras dos partidos na câmara baixa como recurso relevante para a coalizão, sendo totalmente negligenciada a distribuição partidária na câmara alta.

7 Também é necessário diferenciar os gabinetes de coalizão dos gabinetes unipartidários. Porém, isso é mais simples. Basta ver a dispersão de partidos que comandam as pastas ministeriais. Caso existam menos do que dois, não podemos falar em governos de coalizão. 
O Quadro 2 apresenta, de acordo com a literatura, os diferentes casos de presidencialismo de coalizão na América Latina, o número de coalizões formadas em cada governo ${ }^{8}$ e o total de partidos que compuseram o gabinete em algum momento durante o mandato presidencial. Enfim, de todo modo, qualquer que seja a definição a ser seguida, o importante é que se tenha em mente que o presidencialismo de coalizão exige o acordo de dois ou mais partidos políticos para a sua formação, envolvendo não somente uma mera troca de favores entre Executivo e Legislativo, mas sim a perseguição de metas políticas em comum. Caso esse acordo não exista, não podemos falar em governos de coalizão.

Quadro 2 - 0 presidencialismo de coalizão na América Latina

\begin{tabular}{|c|c|c|c|c|c|}
\hline País (N) & Presidente & Mandato & $\begin{array}{c}\text { Qtd. } \\
\text { coalizões }\end{array}$ & $\begin{array}{l}\text { Partido do } \\
\text { Presidente }\end{array}$ & Parceiro(s) de Coalizão \\
\hline \multirow{2}{*}{ Argentina (2) } & De La Rúa & 1999-2001 & 2 & UCR & FREPASO-AR \\
\hline & Macri & 2015-2019 & 4 & PRO & UCR-ARI - UPL \\
\hline \multirow{5}{*}{ Bolívia (5) } & Paz Estensorro & $1985-1989$ & 1 & MNR & ADN \\
\hline & PazZamora & 1989-1993 & 1 & MIR & ADN \\
\hline & Sanchez de Losada I & 1993-1997 & 1 & MNR & UCS-MBL \\
\hline & Banzer & $1997-2002$ & 2 & ADN & MIR-UCS-CONDEPA \\
\hline & Sánchez de Losada II & $2002-2003$ & 2 & MNR & ADN-MIR-UCS \\
\hline \multirow{3}{*}{ Brasil (7) } & Cardosol & $1995-1998$ & 2 & PSDB & PFL - PMDB - PTB - PPB - PPS \\
\hline & Cardosoll & 1999-2002 & 3 & PSDB & PFL - PMDB - PTB - PPB -PPS \\
\hline & Lulal & $2003-2006$ & 4 & PT & $\begin{array}{c}\text { PMDB - PTB - PL - PSB - PPS - } \\
\text { PDT - PCdoB - PV - PP }\end{array}$ \\
\hline
\end{tabular}

8 Considera-se que há a formação de uma nova coalizão (a) quando um presidente inaugura o seu mandato adotando um pacto interpartidário de distribuição de ministérios em troca de apoio legislativo e (b) quando ocorre alguma mudança partidária na composição do gabinete ao decorrer do termo presidencial (AMORIM NETO, 2006). Desse modo, o quadro cobre desde governos, que só tiveram uma coalizão durante todo seu mandato, como o caso das coalizões uruguaias, até os casos brasileiros, em que o governo Lula Il chegou a formar seis coalizões diferentes em um único mandato. 


\begin{tabular}{|c|c|c|c|c|c|}
\hline País (N) & Presidente & Mandato & $\begin{array}{c}\text { Qtd. } \\
\text { coalizões }\end{array}$ & $\begin{array}{l}\text { Partido do } \\
\text { Presidente }\end{array}$ & Parceiro(s) de Coalizão \\
\hline \multirow{4}{*}{ Brasil (7) } & Lula II & $2007-2010$ & 6 & PT & $\begin{array}{c}\text { PMDB - PTB - PSB - PPS - } \\
\text { PCdoB - PV-PR - PP - PDT - PRB }\end{array}$ \\
\hline & Rousseffl & $2011-2014$ & 5 & PT & $\begin{array}{l}\text { PMDB - PP - PR - PSB - } \\
\text { PDT - PCdoB - PRB - PSD }\end{array}$ \\
\hline & Rousseff II & $2015-2016$ & 2 & PT & $\begin{array}{l}\text { PMDB - PP - PR - PCdoB - } \\
\text { PRB - PDT - PSD - PTB - PROS }\end{array}$ \\
\hline & Temer & $2016-2018$ & 1 & PMDB & $\begin{array}{c}\text { PSDB - PP - PSD - PSB- DEM - } \\
\text { PRB - PTB - PPS - PV }\end{array}$ \\
\hline Costa Rica (1) & Alvarado & $2018-\ldots$ & 1 & PAC & PUSC-PLN - CSXXI-FA \\
\hline \multirow{7}{*}{ Chile (7) } & Aylwin & 1990-1994 & 1 & PDC & PR-Psch-PPD \\
\hline & Frei & $1994-2000$ & 1 & PDC & PPD-PSch-PR \\
\hline & Lagos & $2000-2006$ & 1 & PPD & PDC-PSch-PRSD \\
\hline & Bachelet I & $2006-2010$ & 1 & PSch & PDC - PPD - PRSD \\
\hline & Piñeral & $2010-2014$ & 1 & RN & UDI \\
\hline & Bachelet II & $2014-2018$ & 3 & PSch & $\begin{array}{l}\text { PDC - PPD - PRSD - } \\
\text { MAS-IC-PCCh }\end{array}$ \\
\hline & Piñera ll & $2018-\ldots$ & 1 & - & RN - UDI - EVOP \\
\hline \multirow{5}{*}{ Colômbia (5) } & Pastrana & $1998-2002$ & 1 & PC & $P L$ \\
\hline & Uribe I & $2002-2006$ & 3 & $\begin{array}{l}\text { Primero } \\
\text { Colombia }\end{array}$ & $P C-P L-V 0$ \\
\hline & Uribe II & $2006-2010$ & 1 & $\begin{array}{l}\text { Primero } \\
\text { Colombia }\end{array}$ & PC-Partido de la U \\
\hline & Santos I & $2010-2014$ & 1 & $\begin{array}{l}\text { Partido } \\
\text { de la U }\end{array}$ & $P L-P C-C R$ \\
\hline & Santos II & $2014-2018$ & 3 & $\begin{array}{l}\text { Partido } \\
\text { delaU }\end{array}$ & $P L-C R-A V-P C$ \\
\hline \multirow{2}{*}{ Equador (2) } & Borja & 1988-1992 & 3 & ID & PSC - DP \\
\hline & Gutierrez & $2003-2005$ & 1 & PSP & PCK - META - MPD \\
\hline
\end{tabular}




\begin{tabular}{|cccccc|}
\hline \multirow{2}{*}{ País (N) } & Presidente & Mandato & $\begin{array}{c}\text { Qtd. } \\
\text { coalizões }\end{array}$ & $\begin{array}{c}\text { Partido do } \\
\text { Presidente }\end{array}$ & Parceiro(s) de Coalizão \\
\hline \multirow{2}{*}{ Uruguai (4) } & Lacalle & $1990-1995$ & 1 & PN & PC \\
\cline { 2 - 6 } & Sanguinetti ll & $1995-2000$ & 1 & PC & PN \\
\cline { 2 - 6 } & Battle & $2000-2005$ & 1 & PC & PN \\
\cline { 2 - 6 } & Lacalle Pou & $2020-\ldots$ & 1 & PN & PC - CA - PI \\
\hline
\end{tabular}

Fonte: Albala (2017a, 2017b), Amorim Neto (2019) e Camerlo e Martínez-Gallardo (2017). Nota: Quadro elaborado pelos autores.

\section{Novos caminhos}

Nas últimas duas seções, preocupamo-nos, respectivamente, em apresentar a extensão da literatura existente destinada a compreender os governos de coalizão e a conceituar o que são as coalizões presidencialistas. Nesta seção, o nosso propósito é expor o que se discute atualmente no que tange ao presidencialismo de coalizão. Particularmente, o objetivo é mostrar que ainda se tem muito a pesquisar nessa temática. Com isso, pretende-se acalmar aqueles que, porventura, imaginam que o debate acadêmico a respeito do presidencialismo corre o risco de se cessar em virtude da não renovação da agenda de pesquisa, como é o caso de Chaisty, Cheeseman e Power (2014).

\section{A gestão de coalizões e as ferramentas presidenciais}

Os avanços da temática do presidencialismo deixam importante lição para os pesquisadores do presidencialismo multipartidário: é preciso focar o cultivo de alianças interpartidárias heterogêneas no intervalo entre as eleições (POWER, 2015, p. 29). Esse enfoque não é nada novo: Amorim Neto (2006), por exemplo, afirma que os padrões de formação ministerial estão associados às estratégias legislativas. Do mesmo modo, Pereira, Power e Rennó (2005) igualmente destacam a importância da "gestão" da coalizão através da averiguação de como as alianças do chefe do Executivo 
se comportam ao longo do tempo. O ponto é: em que medida essa discussão é relevante?

As coalizões formadas pelos presidentes apresentam forte natureza conflitiva e que podem ser melhor entendidas a partir dos esforços de integração e estabilidade feitos pelos presidentes. Dessa forma, além de se preocuparem com o tamanho de sua aliança e a coalescência de seu gabinete, os presidentes precisam concentrar-se em administrar coalizões instáveis com outras formas de artifício político, tais como o poder de agenda e o uso seletivo de prerrogativas presidenciais (POWER, 2015, p. 32). Em outras palavras, fala-se da "caixa de ferramentas" presidencial. Essa terminologia se remete a nada mais do que ao fato de o presidente possuir uma série de ferramentas a seu dispor para conquistar apoio majoritário no legislativo. $\mathrm{O}$ grande ponto é que a construção de uma coalizão governista é somente um dos modos que o Executivo dispõe para auferir sucesso no Legislativo.

Ao olhar para o caso brasileiro, Raile, Pereira e Power (2011) apontam que existe, ao menos, mais uma ferramenta à vontade do presidente que é capaz de fazer com que as pautas do Executivo sejam aprovadas pelo Legislativo: o controle orçamentário. A ideia é que, mesmo com a formação de um gabinete de coalizão, o sucesso legislativo do Executivo está sujeito ao jogo político diário. Assim, a disponibilização de recursos patronais aos parlamentares funciona como mais uma medida para a garantia de apoio em um Legislativo fragmentado.

A principal contribuição do trabalho de Raile, Pereira e Power (2011, p. 329) é a de que eles destacam que tais ferramentas não são independentes uma da outra, mas sim interdependentes. Como exemplo disso, os autores destacam que os governos de coalizão que são mais coalescentes (ou seja, alocam as pastas ministeriais de forma mais proporcional ao tamanho de cada membro da coalizão na câmara baixa) tendem a despender menos recursos político-financeiros em forma de pork.

Além disso, é importante mencionar a existência de outro estudo que reforça esse argumento de complementaridade entre as duas 
ferramentas presidenciais para o caso brasileiro. Bertholini e Pereira (2017) mostram que coalizões menores, compostas por membros ideologicamente próximos e que alocam os ministérios de forma proporcional ao peso legislativo de cada partido representado no gabinete, costumam gastar menos recursos financeiros no decorrer do mandato.

Todavia, existem espaços para o aprofundamento de ambos os estudos expostos anteriormente, tendo em vista que, além de se restringir somente ao caso brasileiro, o período de análise dos dois trabalhos só cobriu governos de coalizão. Na soma, foram analisados somente os governos de Cardoso I, Cardoso II, Lula I, Lula II e Rousseff I. Apesar de serem importantes por demonstrar o caráter complementar das duas ferramentas (formação de coalizões e controle orçamentário), não se sabe em que medida a disponibilização de recursos para os parlamentares serve como instrumento substituto ao acordo de coalizões.

Como contraponto comparativo, Inácio e Llanos (2015) estudam não somente o caso brasileiro, mas também o argentino. Mais ainda, as autoras apresentam outro artifício a serviço dos presidentes para o gerenciamento das coalizões governamentais: o remanejamento de estruturas burocráticas vinculadas à presidência. Em suma, o argumento é que, como os ministérios são repartidos entre os parceiros da coalizão, a maior centralização das agências burocráticas no chefe do Executivo seria um meio de se adaptar ao cenário político, conduzir mudanças importantes à agenda presidencial e não perder a agência sobre o governo. Ainda assim, existem espaços para o aprofundamento para estudos posteriores. Como exemplo disso, por existir forte componente discricionário por parte do chefe do Executivo, resta saber como os diferentes perfis de presidentes possuem impacto no reordenamento das estruturas burocráticas.

A partir de uma perspectiva comparada mais ampla, Chaisty, Cheeseman e Power (2014) argumentam que, no total, existem cinco ferramentas que os presidentes dispõem para conquistar maiorias legislativas: o poder de agenda, a autoridade orçamentária, a distribuição de ministérios, a influência do poder partidário e o 
funcionamento de instituições informais. Em contraposição aos estudos anteriores, que focaram ou em um único, ou em dois países presidencialistas latino-americanos, Chaisty, Cheeseman e Power buscam entender quais são os típicos instrumentos de governo dos presidentes em três regiões diferentes: a América Latina, os países da antiga União Soviética e, por fim, a África.

O resultado dos autores é que existe uma evidente variedade inter-regional no que concerne ao uso das ferramentas pelos presidentes (CHAISTY; CHEESEMAN; POWER, 2014, p. 8-12). Primeiramente, encontrou-se que os chefes do Executivo latino-americanos habitualmente conquistam apoio legislativo pelo controle do orçamento e da distribuição de ministérios aos partidos da coalizão. Por outro lado, nos países da antiga União Soviética, os instrumentos mais utilizados são o controle da agenda política e o uso da influência partidária. Por fim, na África, os presidentes costumam distribuir as pastas ministeriais e utilizar as instituições informais para que seus projetos sejam aprovados pelo Legislativo.

Desse modo, a questão é que a formação de arranjos de governo é somente uma das ferramentas disponíveis aos presidentes para assegurar uma boa governabilidade. Os estudos mostrados previamente ainda endossam que há uma interação de complementaridade com outras ferramentas. Ou seja, os presidentes costumam combinar dois ou mais instrumentos para garantir uma boa governabilidade. Então, tendo em vista que a lista de ferramentas presidenciais ainda não foi identificada de forma exaustiva, e que existe uma grande variedade de países presidencialistas, são mais do que bem-vindos novos estudos destinados a compreender novas ferramentas e como os presidentes as manuseiam.

\section{A divisão do Legislativo em duas casas: a dinâmica bicameral no presidencialismo}

Outro tema pouco explorado pela literatura é a relação entre o presidencialismo de coalizão e o bicameralismo. É importante ter em mente que os sistemas bicamerais são simplesmente aqueles que dividem o Legislativo em duas casas. A questão é que a negligência 
desse simples traço institucional se torna notável à medida que se percebe que o bicameralismo é habitualmente mais forte nos regimes presidenciais de governo do que nos parlamentaristas (NEIVA, 2006).

Nesse ponto, vale destacar que a força do bicameralismo é mensurado através das dimensões de simetria e congruência (LIJPHART, 1999). A simetria verifica o quão parelhas são as competências constitucionais de ambas as casas, enquanto, por sua vez, a congruência, o quão parecidas são as composições partidárias das duas câmaras legislativas. A partir disso, os sistemas bicamerais fortes são aqueles que são concomitantemente simétricos e incongruentes, já que, desse modo, as câmaras têm preferências distintas, ao passo que têm a mesma capacidade de interferir na tramitação dos projetos de lei.

Com isso, a pergunta que nos resta é: qual exatamente a relevância das forças dos sistemas bicamerais para o jogo político? É possível dizer que, no pior dos casos, um bicameralismo forte faz toda a diferença entre a aprovação ou a rejeição de um projeto. $\mathrm{O}$ ponto é que a existência de mais uma casa legislativa forte implica na adição de mais um veto-player no processo de produção de leis (TSEBELIS, 2002). Nesse sentido, para emplacar as políticas de sua preferência, o chefe do Executivo, ao menos em tese, deve levar em conta também a composição partidária da câmara alta.

De fato, as pesquisas iniciais já apontam que os presidentes se importam sim com a garantia da maioria também nas câmaras altas. Albala (2017b) mostra que as coalizões presidenciais buscam incluir mais parceiros até o dia da posse presidencial a fim de possuir status majoritário em ambas as casas. No entanto, apesar de Albala (2017b) mostrar que as coalizões que asseguram maiorias concorrentes em ambas as casas duram mais do que aquelas que não as asseguram, Albala (2017a) conclui que possuir uma maioria bicameral não implica na existência do mesmo governo de coalizão até o último dia de mandato presidencial. Com efeito, trata-se de um resultado surpreendente, dado que o esperado é que a existência 
de maiorias concorrentes em um Legislativo bicameral forte fosse o suficiente para manter a estabilidade dos pactos de coalizão.

De todo modo, o ponto em que queremos chegar é que ainda existe muito a se contribuir na discussão referente à conexão entre sistemas bicamerais e coalizões presidenciais ${ }^{9}$. Um primeiro exemplo disso é que o próprio estudo de Albala (2017a) se baseia no teste de uma hipótese intuitiva. Desse modo, ainda não se sabe o mecanismo causal que justifica a não durabilidade das coalizões até o fim do mandato presidencial, mesmo quando se assegura maioria em ambas as casas. Como outro exemplo, não se sabe ainda a relação entre a coalescência dos gabinetes presidenciais e a distribuição partidária dos assentos das câmaras altas, uma vez que o cálculo da coalescência se baseia única e exclusivamente na dispersão de cadeiras das câmaras baixas.

Ademais, não se deve perder de vista a relação entre sistemas bicamerais e as "ferramentas" disponíveis para o presidente. Ou seja, será que os presidentes utilizam outras ferramentas para contornar a fragmentação do Legislativo em duas casas que não somente a distribuição de pastas ministeriais aos partidos políticos?

Por fim, deve-se atentar que quem exerce a função de presidente do Senado é justamente o vice-presidente em alguns países. Como exemplo, essa afirmação é válida para países como Argentina e Uruguai. Com isso, mais do que um mero conjunto de instituições legislativas, o bicameralismo se mostra aninhado em uma ampla rede institucional. Ao menos para a América Latina, a sua relação com a vice-presidência é relevante à medida que, além de não ser nada extraordinário o número de vices que participam como membros ou presidentes das câmaras altas (BIDEGAIN, 2017), a literatura destinada a compreender a importância da

9 No entanto, deve-se ter atenção no momento de construção dos desenhos de pesquisa que envolvam o bicameralismo e o presidencialismo de coalizão. A princípio, alguns países bicamerais latino-americanos não possuem governos recentes de coalizão, como são os exemplos da Bolívia e do Peru. Além disso, não é possível comparar a influência dos sistemas bicamerais fortes e fracos sobre os gabinetes de coalizão na América Latina, já que a região é basicamente composta por casas legislativas simétricas entre si (HELLER; BRANDUSE, 2014; LLANOS; NOLTE, 2003). Como consequência disso, não existem sistemas bicamerais exatamente fracos na América Latina, mas bicameralismos com poderes fortes ou intermediários. 
vice-presidência para a política se mostra ainda muito incipiente (LOPES, 2019). Não custa ressaltar que o papel dos vice-presidentes não se vincula estritamente somente com a dinâmica bicameral, sendo também significativo no processo eleitoral e na condução da agenda política do governo.

Desse modo, não é somente a literatura bicameral que carece de aprofundamento, mas também os próprios estudos destinados a compreender a função dos vice-presidentes no presidencialismo de coalizão. Será que o fato de os vices ocuparem cargos relevantes nas câmaras altas influencia o cálculo feito pelos candidatos à presidência no processo de construção dos acordos e das chapas eleitorais? Enfim, essa e muitas outras perguntas referentes aos dois temas ainda continuam sem resposta.

\section{A construção de coalizões pré-eleitorais e a congruência federal das coalizões}

Por ora, restringimo-nos a apresentar somente os acordos de coalizão como um fenômeno pós-eleições. Porém, na prática, existem partidos que não lançam o seu próprio candidato à presidência com o propósito de apoiar a/o aspirante ao cargo de presidente alheio. Ora, qual é o sentido de se formarem coalizões pré-eleitorais? Para os partidos que lançam candidatos presidenciais, a formação de acordos antes das eleições ajuda na eleição dos seus próprios candidatos (FREUDENREICH, 2016). Por outro lado, embora não seja possível obrigar o presidente a cumprir com os acordos feitos antes das eleições no que tange à distribuição de ministérios, os partidos que decidem apoiar o candidato de outrem na corrida presidencial são capazes de desfrutar da execução de políticas públicas mais próximas das suas preferências (KELLAM, 2017). Isso ocorre porque, com o propósito de aumentar a captação de votos, as agendas políticas de cada candidato à presidência são amplamente publicizadas durante as eleições. Assim, os partidos membros da coalizão pré-eleitoral possuem a oportunidade de influenciar a agenda dos seus parceiros e, em caso de vitória, existe um constrangimento para o não cumprimento das promessas 
relacionadas às políticas públicas feitas durante a campanha eleitoral. Desse modo, Kellam (2017, p. 18) sustenta que a formação das coalizões pré-eleitorais, sob a ótica dos partidos que não lançam candidatos, é capaz de ajudar os partidos a alcançarem objetivos relacionados às policies, embora não seja garantidora para os relacionados ao office.

Entretanto, o não lançamento de um candidato às eleições presidenciais pode ter outro motivo. Ao invés de focar nas eleições presidenciais, os partidos podem preferir concentrar esforços nas eleições executivas subnacionais como forma de nacionalização das suas estruturas partidárias (BORGES; ALBALA; BURTNIK, 2017). Com isso, mais do que uma estratégia a plano nacional, o fato de não lançar candidatos para a disputa do maior prêmio do Executivo se mostra também como um plano ao nível regional.

Nesse ponto, é importante não esquecer que a coligação para a corrida presidencial gera consequências para o resultado das eleições legislativas. Borges e Turgeon (2019), ao estudarem as coalizões no Brasil e no Chile, concluem que a realização de um acordo pré-eleitoral para a corrida presidencial beneficia tanto o partido presidencial quanto os demais coligados no que diz respeito à quantidade de votos recebidos pelos membros de cada um na corrida ao Legislativo. Com efeito, Borges e Turgeon (2019, p. 7-9) ainda ressaltam que quem mais se beneficia em termos de votos no Legislativo são os partidos localizados mais próximos ideologicamente do partido presidencial e o próprio partido do presidente.

Como últimas descobertas da literatura, ao invés de serem a exceção, as coalizões pré-eleitorais têm sido, na verdade, a regra no presidencialismo de coalizão latino-americano. Recentemente, as coalizões pré-eleitorais têm sido relacionadas tanto ao alcance do status majoritário do governo no período pós-eleitoral (BORGES; TURGEON; ALBALA, 2020) quanto à própria duração dos próprios governos de coalizão (ALBALA, 2020).

De todo modo, a influência das coalizões pré-eleitorais presidenciais sobre as eleições legislativas não é a única forma de compartilhamento de votos entre os processos eleitorais. Com efeito, a relação 
entre as eleições para o Executivo e para o Legislativo em âmbito nacional se configura somente como uma influência horizontal, já que ambas ocorrem em nível nacional. Não se deve esquecer que, em sistemas federativos, existe, por outro lado, a relação entre as eleições nacionais e subnacionais. Nesse quesito, Mauro (2018) discorre que há uma tendência à formação de coalizões congruentes quando as eleições para ambos os níveis são concorrentes. Porém, até mesmo outro fator pode justificar a transversalidade federal das coalizões: a falta de heterogeneidade social na cultura política (ERRINGTON, 2018).

Em síntese, o ponto é que, embora seja crescente o número de trabalhos com o propósito de estudar a formação de coalizões em momentos pré-eleitorais e as coalizões em níveis federal e subnacional, a discussão ainda se mostra embrionária. Como prova disso, todos os estudos citados neste tópico não datam de antes de 2015. Desse modo, não se descartam novos estudos que ampliem o horizonte nessas temáticas. Uma grande possibilidade de pesquisa é o endereçamento de projetos relacionados ao presidencialismo em outras partes do mundo que não a América Latina. Embora os países latino-americanos sejam, sem dúvida, importantes locus de análise, eles não são os únicos países presidencialistas no mundo. O próprio trabalho de Chaisty, Cheeseman e Power (2014) abarcou regimes presidenciais africanos e da antiga União Soviética, sem contar que ainda há países presidencialistas no Leste Asiático, tais como as Filipinas, a Indonésia e as Maldivas.

\section{Considerações finais}

O fenômeno das coalizões não se restringe a alguns países, podendo ser observado ao redor do mundo como um caminho para se governar em contextos democráticos. A sua combinação com o presidencialismo, como demonstrado ao longo do presente trabalho, herda uma grande tradição parlamentarista, que, a princípio, atestou a impossibilidade dessa combinação e, até mesmo, o fracasso do presidencialismo em manter regimes democráticos. Entretanto, a formação de coalizões sob regimes presidenciais já foi verificada 
empiricamente por diversos autores, e o avanço da temática esteve em compasso com desenhos comparados (POWER, 2005).

Acima de tudo, a grande descrença que pode pairar a respeito das coalizões como uma forma plausível, sólida e moralmente aceitável de se governar deriva, em grande parte, de um desconhecimento acerca da maneira como muitos países governam. Diferentemente do que se pensa, governar por meio de "alianças" não é um fenômeno exclusivo ao Brasil e muito menos intrinsecamente atrelado às práticas políticas clientelistas e fisiologistas. Com efeito, a construção de governos de coalizão exige o estabelecimento de acordos interpartidários e o compartilhamento de recursos entre os membros com o propósito de alcançar metas estabelecidas em conjunto e sustentar governos minimamente estáveis.

A literatura sobre coalizões possui diferentes fases com distintos enfoques e problemas de pesquisa, desde os estudos iniciais interessados em coalizões somente como grupos de indivíduos que operam em um ambiente totalmente neutro até a última geração de trabalhos preocupada em como as coalizões de âmbito regional e nacional se relacionam. Inicialmente, um dos objetivos deste trabalho foi situar onde o presidencialismo de coalizão se enquadra nessa ampla literatura internacional sobre coalizões (coalition theories). A partir disso, discutiu-se a definição do que se entende como presidencialismo de coalizão, sendo destacados especialmente a necessidade de um pacto factível entre dois ou mais partidos e o alerta de que a presença de ministros partidários não é suficiente para nomear dado governo como de coalizão. Por fim, procurou-se mostrar que a discussão sobre a coalizão em regimes presidenciais, apesar de ser frutífera, ainda não alcançou seu plateau. A literatura sobre o presidencialismo de coalizão ainda carece de estudos que sejam capazes de explicar como os presidentes lançam mão de diferentes mecanismos para administrarem as suas alianças, o impacto do arranjo bicameral na formação e na duração dos governos de coalizão e o aspecto temporal das alianças interpartidárias.

Entende-se que o principal aporte deste trabalho foi exaltar o debate acadêmico envolto ao presidencialismo de coalizão, ainda 
mais em um momento no qual as coalizões são entendidas especialmente como uma prática nefasta de trocar favores políticos particularistas. A partir da discussão apresentada, a expectativa é de que o debate acadêmico sobre o presidencialismo de coalizão não se limite apenas à visão simplória do “toma lá, da cá”. Mais ainda, por meio da apresentação do presidencialismo de coalizão em outros países latino-americanos, é de se esperar ganhos ao debate brasileiro. Embora seja, de fato, interessante e importante para a teoria e para a compreensão da política brasileira, o presidencialismo de coalizão brasileiro representa somente um caso em meio a uma miríade de coalizões governamentais em regimes presidenciais. Nesse sentido, uma revolução de estudos comparados na área se faz mais do que necessária, mas, sim, urgente.

\section{Referências}

ABRANCHES, Sérgio. Presidencialismo de coalizão: o dilema institucional brasileiro. Dados - Revista de Ciências Sociais, Rio de Janeiro, v. 31, n. 1, p. 5-38, 1988.

ABRANCHES, Sérgio. Presidencialismo de coalizão: raízes e evolução do modelo político brasileiro. São Paulo: Companhia das Letras, 2018. ALBALA, Adrián. Coalition presidentialism in bicameral congresses: how does the control of a bicameral majority affect coalition survival? Brazilian Political Science Review, São Paulo, v. 11, n. 2, p. 1-27, 2017a.

ALBALA, Adrián. Presidential coalitions under bicameralism: how bicameral majorities impact the formation and conclusion processes. British Journal of Politics and International Relations, Oxford, v. 19, n. 4, p. 735-754, $2017 \mathrm{~b}$.

ALBALA, Adrián. The missing piece: introducing the 4 th generation of coalition theories. In: ALBALA, Adrián; RENIU, Josep (ed.). Coalition politics and federalism. Cham: Springer International, 2018. p. 13-32.

ALBALA, Adrián. When do coalitions form under presidentialism, and why does it matter? A configurational analysis from Latin America. Politics, [Online], p. 1-20, 2020. 
ALBALA, Adrián; RENIU, Josep. Coalition politics and federalism.

Cham: Springer International, 2018.

ALEMÁN, Eduarno; TSEBELIS, George. Political parties and government coalitions in the Americas. Journal of Politics in Latin America, [Online], v. 3, n. 1, p. 3-28, 2011.

AMORIM NETO, Octavio. Formação de gabinetes ministeriais no Brasil: coalizão versus cooptação. Nova Economia, [Online], v. 4, n. 1, p. 9-34, 1994.

AMORIM NETO, Octavio. Cabinet formation in presidential regimes: an analysis of 10 Latin American countries. In:MEETING OF THE LATIN AMERICAN STUDIES ASSOCIATION, 24-26 set. 1998, Chicago. Papers [...]. Chicago: LASA, 1998. p. 1-36. Disponível em: http://biblioteca.clacso.edu.ar/ar/libros/lasa98/ Amorim.pdf. Acesso em: 19 fev. 2021.

AMORIM NETO, Octavio. Cabinets and coalitional presidentialism. In: AMES, Barry (ed.). Routledge Handbook of Brazilian Politics. New York: Routledge, 2019. p. 293-312.

AMORIM NETO, Octavio. Gabinetes presidenciais, ciclos eleitorais e disciplina legislativa no Brasil. Dados - Revista de Ciências Sociais, Rio de Janeiro, v. 43, n. 3, p. 479-519, 2000.

AMORIM NETO, Octavio. The presidential calculus: executive policy making and cabinet formation in the Americas. Comparative Political Studies, Thousand Oaks, v. 39, n. 4, p. 415-440, 2006.

ARAÚJO, Victor; SILVA, Thiago; VIEIRA, Marcelo. Measuring presidential dominance over cabinets in presidential systems: constitutional design and power sharing. Brazilian Political Science Review, São Paulo, v. 10, n. 2, p. 1-23, 2016.

AXELROD, Robert. Conflict of interest: a theory of divergent goals with applications to politics. Chicago: Markham, 1970.

BERTHOLINI, Frederico; PEREIRA, Carlos. Pagando o preço de governar: custos de gerência de coalizão no presidencialismo brasileiro. Revista de Administração Pública, [Online], v. 51, n. 4, p. 528-550, 2017. 
BIDEGAIN, Germán. Vicepresidentes en América del Sur: una agenda de investigación. Colombia Internacional, [Online], n. 89, p. 161-190, 2017.

BORGES, André. Federalism, party politics and coalition dynamics. In: AMES, Barry (ed.). Routledge Handbook of Brazilian Politics. New York: Routledge, 2019. p. 175-201.

BORGES, André; ALBALA, Adrián.; BURTNIK, Lucia. Pathways to nationalization in multilevel presidential systems: accounting for party strategies in Brazil and Argentina. Publius - The Journal of Federalism, [Online], v. 47, n. 4, p. 648-672, 2017.

BORGES, André; LLOYD, Ryan. Presidential coattails and electoral coordination in multilevel elections: comparative lessons from Brazil. Electoral Studies, Oxford, v. 43, n. 1, p. 104-114, 2016.

BORGES, André; TURGEON, Mathieu. Presidential coattails in coalitional presidentialism. Party Politics, London, v. 25, n. 2, p. 192-202, 2019.

BORGES, André; TURGEON, Mathieu; ALBALA, Adrián. Electoral incentives to coalition formation in multiparty presidential systems. Party Politics, London, p. 1-11, 2020.

BROWNE, Eric. Testing theories of coalition formation in the European context. Comparative Political Studies, Thousand Oaks, v. 3, n. 4, p. 391-412, 1971.

BROWNE, Eric; FRANKLIN, Mark. Aspects of coalition payoffs in European parliamentary democracies. American Political Science Review, Washington, D. C., v. 67, n. 2, p. 453--469, 1973. BROWNE, Eric; FRANKLIN, Mark. New directions in coalition research. Legislative Studies Quarterly, Iowa City, v. 11, n. 4, p. 469-483, 1986.

BROWNE, Eric; RICE, Peter. A bargaining theory of coalition formation. British Journal of Political Science, Cambridge, v. 9, n. 1, p. 67-87, jan. 1979.

BUDGE, Ian; LAVER, Michael. The policy basis of government coalitions: a comparative investigation. British Journal of Political Science, Cambridge, v. 23, n. 4, p. 499-519, 1993. 
CAMERLO, Marcelo; MARTÍNEZ-GALLARDO, Cecilia. Government formation and minister turnover in presidential cabinets: comparative analysis in the Americas. New York: Routledge, 2017.

CAPLOW, Theodore. Further development of a theory of coalitions in the triad. American Journal of Sociology, Chicago, v. 64, n. 5, p. 488-493, 1959.

CAREY, John. Presidential versus parliamentary government. In: MENARD, Claude; SHIRLEY, Mary (ed.). Handbook of New Institutional Economics. Dordrecht: Springer, 2005. p. 91-122.

CARROLL, Royce; COX, Gary. The logic of Gamson's Law: pre-election coalitions and portfolio allocations. American Journal of Political Science, Madison, v. 51 n. 2, p. 300-313, 2007.

CHASQUETTI, Daniel. Democracia, multipartidismo y coaliciones en América Latina: evaluando la difícil combinación. In: LANZARO, Jorge (ed.). Tipos de presidencialismo y coaliciones politicas en America Latina. Buenos Aires: CLACSO, 2001. p. 319-359.

CHASQUETTI, Daniel. La supervivencia de las coaliciones presidenciales de gobierno en América Latina. POSTData Revista de Reflexión y Análisis Políitico, Buenos Aires, n. 11, p. 163-192, 2006.

CHAISTY, Paul; CHEESEMAN, Nic; POWER, Timothy. Rethinking the 'presidentialism debate': conceptualizing coalitional politics in cross-regional perspective. Democratization, Essex, v. 21, n. 1, p. 72-94, 2014.

CHEIBUB, José Antônio. Presidentialism, parliamentarism, and democracy. New York: Cambridge University Press, 2007.

CHEIBUB, José Antônio; PRZEWORSKI, Adam; SAIEGH, Sebastian. Government coalitions and legislative success under presidentialism and parliamentarism. British Journal of Political Science, Cambridge, v. 34, n. 4, p. 565-587, 2004. 
CHIRU, Mihail. Early marriages last longer: pre-electoral coalitions and government survival in Europe. Government and Opposition, London, v. 50, n. 2, p. 165-188, 2015.

CLERICI, Paula Andrea; SCHERLIS, Gerardo. La regulación de alianzas electorales y sus consecuencias en sistemas multinivel en América Latina. Revista Electrónica del Instituto de Investigaciones “Ambrosio L. Gioja”, Buenos Aires, ano VIII, n. 12, p. 77- 98, 2014.

DEBUS, Marc. Pre-electoral commitments and government formation. Public Choice, Dordrecht, v. 138, n. 1, p. 45- 64, 2009.

DEHEZA, Grace Ivana. Gobiernos de coalición en el sistema presidencial: América del Sur. 1997. Tese (Doutorado) European University Institute, Firenze, 1997.

DE SWAAN, Abram. Coalition theories and cabinet formations. Amsterdam: Elsevier, 1973.

ERRINGTON, Wayne. Long-term patterns of coalition-building at state and federal level in Australia. In: ALBALA, Adrián; RENIU, Josep (ed.). Coalition politics and federalism. Cham: Springer International, 2018. p. 165-177.

FRANKLIN, Mark.; MACKIE, Thomas. Familiarity and inertia in the formation of governing coalitions in parliamentary democracies. British Journal of Political Science, Cambridge, v. 13, n. 3, p. 275-298, 1983.

FREUDENREICH, Johannes. The formation of cabinet coalitions in presidential systems. Latin American Politics and Society, Coral Gables, v. 58, n. 4, p. 80-102, 2016.

GAMSON, William. A theory of coalition formation. American Sociological Review, Washington, D. C., v. 26, n. 3, p. 373-382, 1961.

GARRETÓN, Manuel Antonio. Revisando las transiciones democráticas en América Latina. Nueva Soecidad, [Online], n. 148, p. 20-29, 1997.

GOLDER, Sona. Pre-electoral coalition formation in parliamentary democracies. Bristish Journal of Political Science, [Online], v. 36, n. 2, p. 193-212, 2006. 
HELLER, William; BRANDUSE, Diana. The politics of bicameralism. In: MARTIN, Shane; SAAFELD, Tthomas; STROM, Kaare (ed.). The Oxford Handbook of Legislative Studies. Oxford: Oxford University Press, 2014. p. 332-351.

INÁCIO, Magna; LLANOS, Mariana. The institutional presidency from a comparative perspective: Argentina and Brazil since the 1980s. Brazilian Political Science Review, São Paulo, v. 9, n. 1, p. 39-64, 2015.

INDRIDASON, Indridi. Live for today, hope for tomorrow? Rethinking Gamson's Law. Working Paper from the Department of Political Science of the University of California,Riverside, p. 1-34, 2015.

KELLAM, Marisa. Why pre-electoral coalitions in presidential systems? British Journal of Political Science, Cambridge, v. 47, n. 2, p. 391-411, 2017.

LAVER, Michael; SCHOFIELD, Norman. Multiparty government: the politics of coalition in Europe. Oxford: Oxford University Press, 1990.

LEISERSON, Michael. Coalition in politics: a theoretical and empirical study. 1966. Thesis (PhD) - Yale University, Yale, 1966.

LIJPHART, Arend. Parliamentary versus presidential government. Oxford: Oxford University Press, 1992.

LIJPHART, Arend. Patterns of democracy: government forms and performance in thirty-six countries. Yale: Yale University Press, 1999.

LINZ, Juan. Presidential or parliamentary democracy: does it make a difference? In: LINZ, Juan; VALENZUELA, Arturo (ed.). The failure of presidential democracy. Baltimore, M. D.: Johns Hopkins University Press, 1994. p. 3-90.

LINZ, Juan. The breakdown of democratic regimes: crisis, breakdown, and reequilibration. Baltimore, M. D.: Johns Hopkins University Press, 1978.

LINZ, Juan. The perils of presidentialism. Journal of Democracy, Baltimore, v. 1, p. 50-69, 1990. 
LLANOS, Mariana; NOLTE, Detlef. Bicameralism in the Americas: around the extremes of symmetry and incongruence. Journal of Legislative Studies, Essex, v. 9, n. 3, p. 54-86, 2003.

LOPES, Amanda Vitória. De decorativo para protagonista: uma análise sistemática da literatura sobre a vice-presidência na América Latina. In: CONGRESO NACIONAL DE CIENCIA POLÍTICA, 14., 19-20 jul. 2019, San Martín. Pronencias [...]. San Martín: SAAP/UNSAM, 2019. p. 1-19. Disponível em: https://cutt.ly/rlexfmB. Acesso em: 19 fev. 2021.

LUEBBERT, Gregory. Coalition theory and government formation in multiparty democracies. Comparative Politics, New York, v. 15, n. 2, p. 235-249, 1983.

MAINWARING, Scott. Presidentialism, multipartism and democracy: the difficult combination. Comparative Political Studies, Thousand Oaks, v. 26, n. 2, p. 193-228, 1993.

MAURO, Sebastián. Coalition politics in a federalized party system: the case of Argentina. In: ALBALA, Adrián; RENIU, Josep (ed.). Coalition politics and federalism. Cham: Springer International, 2018. p. 113-128.

MORELLI, Massimo. Demand competition and policy compromise in legislative bargaining. American Political Science Review, Washington, D. C., v. 93, n. 4, p. 809-820, 1999.

NEIVA, Pedro. Os determinantes da existência e dos poderes das câmaras altas: federalismo ou presidencialismo. Dados - Revista de Ciências Sociais, Rio de Janeiro, v. 49, n. 2, 269-299, 2006.

PEREIRA, Carlos; POWER, Timothy; RENNÓ, Lucio. Under what conditions do presidents resort to decree power? Theory and evidence from the Brazilian case. The Journal of Politics, Malden, v. 67, n. 1, p. 178-200, 2005.

POWER, Timothy. Presidencialismo de coalizão e o design institucional no Brasil: o que sabemos até agora? In: SATHLER, André; BRAGA, Ricardo (ed.). Legislativo pós-1988: reflexões e perspectivas. Brasília: Câmara dos Deputados, 2015. p. 15-45. PRIDHAM, Geoffrey. Coalitional behavior in theory and practice. Cambridge: Cambridge University Press, 1986. 
RAILE, Eric; PEREIRA, Carlos; POWER, Timothy. The executive toolbox: building legislative support in a multiparty presidential regime. Political Research Quarterly, Salt Lake City, v. 64, n. 2, p. 323-334, 2011.

RENIU, Josep; ALBALA, Adrán. Los gobiernos de coalición y su incidencia sobre los presidencialismos latinoamericanos: el caso del Cono Sur. Estudios Políticos, México, D. F., v. 9, n. 26, p. 161-214, 2012.

RIKER, William. The theory of political coalitions. New Heaven: Yale University Press, 1962.

SHUGART, Matthew; CAREY, John. Presidents and assemblies: constitutional design and electoral dynamics. Cambridge: Cambridge University Press, 1992.

STEPAN, Alfred; SKATCH, Cindy. Constitutional frameworks and democratic consolidation. World Politics, Baltimore, v. 46, n. 1, p. 1-22, 1993.

STROM, Kaare. Minority government and majority rule. Cambridge: Cambridge University Press, 1990.

STROM, Kaare; BUDGE, Ian; LAVER, Michael. Constraints on cabinet formation in parliamentary democracies. American Journal of Political Science, Madison, v. 38, n. 2, p. 303-335, 1994.

TSEBELIS, George. Veto players: how political institutions work. Princeton, NJ: Princeton University Press, 2002.

VALENZUELA, Arturo. Party politics and the crisis of presidentialism in Chile: a proposal for a parliamentary form of government. In: LINZ, Juan.; VALENZUELA, Arturo (ed.). The failure of presidential democracy. Baltimore, M. D.: Johns Hopkins University Press, 1994. p. 91-150.

VANDUSKY-ALLEN, Julie; HELLER, William. Bicameralism and the logic of party organization. Comparative Political Studies, Thousand Oaks, v. 47, n. 5, p. 715-742, 2013. 


\section{Resumo}

O presente artigo busca lidar com a conceituação teórica do que se configura como "presidencialismo de coalizão". Através da apresentação da teoria das coalizões (coalition theories), argumenta-se que a discussão e o próprio entendimento sobre o presidencialismo de coalizão são apenas uma ramificação de uma longa literatura existente sobre as coalizões governamentais. Em vista disso, um dos objetivos do trabalho é mostrar que o presidencialismo de coalizão não é um fenômeno tipicamente brasileiro. Na verdade, existe uma longa tradição de governos de coalizão em outros países latino-americanos. Por fim, mesmo que já tenha sido extensivamente estudado, vê-se que ainda existe muito a ser pesquisado na temática dentre o presidencialismo de coalizão. Assim, explora-se o conceito de coalizões, colocando-o em perspectiva com o presidencialismo e, ao final, analisam-se os possíveis novos caminhos de pesquisa nessa temática.

Palavras-chave: Presidencialismo. Coalizões. América Latina. Governos multipartidários.

\section{Abstract}

This article aims to provide a theoretical account of coalitional presidentialism. After presenting coalition theories as a whole, we argue that the study of presidential coalitions is but one branch of a broader field of studies. As a result, one of our main objectives is to show that presidential coalition governments are not only a Brazilian phenomenon. Indeed, there is a long tradition of multiparty cabinets in other Latin American countries, for instance. To conclude, although much research had already been carried out, we list several topics within the framework of presidential coalitions that have not yet been studied in depth. We thus delve into the concept of coalitions, consider them under presidentialism, and look at possible cutting-edge themes of research within presidential coalition studies.

Keywords: Presidentialism. Coalitions. Latin America. Multiparty governments.

Recebido em 03 de agosto de 2020

Aprovado em 19 de janeiro de 2021 